\title{
Basic foundations for building cognitive skills and expertise
}

\author{
Marcel Martin ${ }^{1,2 *}$, Paul Ouellet ${ }^{3,4}$ and Zeesham Aslam ${ }^{5,6}$ \\ ${ }^{1}$ Retired professor of surgery, Université de Sherbrooke, Sherbrooke, Quebec, Canada \\ ${ }^{2}$ Staff physician, Critical Care Department, Dr Everett Chalmers Hospital, Horizon Health Authority, New Brunswick, Canada \\ ${ }^{3}$ Adjunct Professor, Department of Surgery, Université de Sherbrooke, Sherbrooke, Quebec, Canada \\ ${ }^{4}$ Clinical consultant, Vitalité Health Authority, North West Zone, New Brunswick \\ ${ }^{5}$ Director of Critical Care, Dr Everett Chalmers Hospital, Horizon Health Authority, New Brunswick, Canada \\ ${ }^{6}$ Assistant Professor, Department of Critical Care - Internal Medicine, Dalhousie University, Halifax, Nova Scotia, Canada
}

\begin{abstract}
To build towards expertise, one has to accept to modify his way of practicing, including: 1) A need to reflect on and about the action, 2) A continuous concern about our competence to practice, 3) Tireless effort to combine metacognition and mental practice in a trans-disciplinary approach, 4) Practice cannot be complete without adding research with neuroscience, understanding neuroplasticity, modulation and artificial intelligence.
\end{abstract}

\section{Introduction}

Continuous education is a mandatory condition of practice 'sine qua non' to maintain at least a competence in 'complex system' like medicine [1,2]. Continuous education should not mean intermittent one with inappropriate activities to learn and retain during these active practicing years. Retrospectively, the pre doctoral 'Problem Based Learning' (PBL) approach alone has been an incomplete one mainly used for decision-making and theoretical knowledge training [3]. The practical field of procedural knowledge has been left aside in curriculum like the development of spatial intelligence [4].

These reductionist aspects of our curriculum in medicine led to an incomplete metacognition development [5] where procedural knowledge, third space visualisation, anatomy and spatial intelligence were neglected.

Flexner [6] in his time mandates continuity in pre/postdoctoral and continuous education curriculum. This remained only a dream and continuous education has now to be rebuilt again with a complete change in philosophy [7]. In our present work, we insisted on simulation laboratory [8] as an opening to an integration of procedural knowledge, mixed with decision-making, intuition, uncertainties $[9,10]$ empathy, resilience [11], development of spatial intelligence and creativity. We feel all of the above must be approached in simulation with a global philosophy including technical and non-technical skills and kinetics of decision-making, interdisciplinary approach for both procedural and theoretical knowledge. All those learning elements are included in complex scenarios.

From the world of simulation, the second part of the revolution is the inclusion of neuroscience 12] in cognitive psychology to develop a better metacognition [13] and allow a personalised approach in the development of expertise 14]. The neuroenhancement phenomenon 15], based on neuroplasticity [16] and epigenetics [17] needs to be included for the understanding of neuroplasticity, connectomics [18] and neuroimaging [19]. The anatomical follow up of the neuroplasticity during training is not only possible but also mandatory to study the beneficial aspects of training with functional magnetic resonance imaging (fMRI) to see the anatomical results of this training [20]. The final aspect of this revolution must be the 'Mental Practice' [21] with the understanding of 'Motor to Mental Gradient' in skill learning [22,23].

Skill learning should include gradient between cognition, plasticity, epigenetics [24], modification following physical exercise [25] and their influence on learning. All of these elements will finally help in understanding metacognition and contextualisation of knowledge. We are witnessing a post simulation era where mental world and practice with virtual reality would replace the actual simulation laboratory.

One appropriate question is raised. Why such a presentation on cognition at a biotechnology congress? Three main facts transpire.

1- In cognitive psychology, we are utilising more and more 'Technology-Enhanced Education' (TEE).

2- Our learning approach in medicine is partly transferable to 'Science, Technology, Engineering and Mathematics' (STEM) and biotechnology education.

Therefore it is fair to say that in complex systems, learning should more and more be focused on a trans disciplinary approach. In cognitive neuroscience, the extended knowledge of different

*Correspondence to: Prof. Marcel Martin, Staff physician, Critical Care Department, Dr Everett Chalmers Hospital, Horizon Health Authority, New Brunswick, Canada, E-mail: Marcel.Martin@Usherbrooke.ca

Key words: continuous medical education, practical knowledge decision-making, simulation laboratory and post-simulation era, neuroscience with modulators, mental practice and artificial intelligence

Received: September 07, 2016; Accepted: December 21, 2016; Published: December 26, 2016 
cognitive style (metacognition) based on Beta/Teta Ratio [26] following neurofeedback may help to understand the Brain-Computer-InterfaceMental Imagery (BCI-MI) illiteracy in motor imagery. An important question arises from in the type of training involving spacial intelligence and meditation in trying to facilitate BCI-MI performance [27].

\section{Simulation}

Five main subjects are thoroughly discussed in Simulation laboratory literature:

1- Scenarios with more or less high fidelity,

2- Complex scenarios,

3- Near work space teaching (in situ) with debriefing [28],

4- Teaching in a distributed fashion [29], with or without cognitive task analysis [30]

5-Decomposition of movements [31], consisting of multidisciplinary approach [32] with videocameras [33] for further modeling [34].

For the last twenty years these laboratories have been the revolutionary tools in teaching medicine. Digging on metacognition and cognitive psychology and because of the understanding of the Motor to Mental Gradient in skill learning in sports, mental representation and mental practice started recently to complement the physical practice and to replace it almost completely. Parallel to this approach, neuroscience has helped to understand neuroplasticity, epigenetics and connectomics. Neuroimaging offers a possible follow-up on the road towards expertise.

\section{Mental practice and neuroenhancers}

Mental practice and representation with all the other neuroenhancers described recently at least five elements; three of which are environmental (1-3) and two are structural (4-5)

1- Exercise [25]

2- Practice [35]

3- Videogames [36]

4- Biochemical approach with methylene blue or methylphenidate 37]

5- Electro-mechanical stimulation of the brain [38]

Some authors hypothesize the concept of cognitive reserve with proxy measurements while some of the elements in cognitive reserve can also be modified by mental practice or neuroenhancers [39]. All of these measurements mandate a strategic approach [40] and a strict neuroethics [41]. With the recent description of asymptotic [42] curve of expertise, the use of a global strategic approach will contribute to achieve expertise in complex systems. In the coming years, the methodology for efficient learning will change drastically. Result evaluation is mandatory. Recent literature on cognitive psychology is rapidly growing. One example is with the use of music instrument in learning toward neuroplasticity [43], coupled with physical exercise [44] and mental practice with mindfulness meditation [45] to control emotional stress and learning. Among the enhancement literature, Hardy et al. proved the effect of cognitive enhance learning (Videogame Lumosity) in the Grand Index Score being enhanced in speed of processing, short term memory, working memory, problem solving and fluid reasoning assessments [46]. Alam and Leblanc have shown that multiple choice scores can be optimized with E-learning sessions by combining mental practice with modeling [47]. Several combinations of enhancement are possible and the operation strategy must be studied in different situations.

\section{Summary}

This reflective revolution in education should also include the development of artificial intelligence in a brain-machine interface. However, the application of brain-machine interface mandates a brain control over the machine. Robotics must not replace human brain but must enhance its possibilities. Integration and adaptation must prevail in any learning approach. On the other hand, neuroscience and cognition especially in inhibitory:excitatory (I:E) balance synapses [48] concerning neuroplasticity, should be better understood to optimize the strategy of Targeted Neuroplasticity Training (TNT). By achieving better understanding of cognition and metacognition with neuroimaging, we feel global knowledge will evolve on two fronts : 1- Precision in education with personalized cognition and 2With combined utilization of neuroscience, artificial intelligence and metacognition evolution will reach for solving the recent asymptote curve of expertise but not without a strict necessity of neuroethics.

\section{References}

1. Papachristofi O, Jenkins D, Sharples LD (2016) Assessment of learning curves in complex surgical interventions: a consecutive case-series study. Trials 17: 266. [Crossref]

2. Koh GC (2016) Revisiting the 'Essentials of problem-based learning'. Med Educ 50: 596-599. [Crossref]

3. Servant VF, Schmidt HG (2016) Revisiting 'Foundations of problem-based learning: some explanatory notes'. Med Educ 50: 698-701. [Crossref]

4. Langlois J, Bellemare C, Toulouse J, Wells GA (2015) Spatial abilities and technical skills performance in health care: A systematic review. Medical Education 49:10651085 .

5. Sternberg RJ (1998) Metacognition, abilities and developing expertise: What makes an expert student? Instructional Science 26: 127-140.

6. Arky RA (2006) Shattuck Lecture. The family business--to educate. $N$ Engl J Med 354: 1922-1926.

7. Whitcomb ME (2016) Transforming Medical Education: Is competency-based medical education the right approach? Academic Medicine 91: 618-620.

8. Bond W, Kuhn G, Binstadt E, Quirk M, Wu T, et al. (2008) The use of simulation in the development of individual cognitive expertise in emergency medicine. Acad Emerg Med 15: 1037-1045. [Crossref]

9. Kepecs A (2013) The uncertainty of it all. Nat Neurosci 16: 660-662. [Crossref]

10. Han PK, Klein WM, Arora NK (2011) Varieties of uncertainty in health care: a conceptual taxonomy. Med Decis Making 31: 828-838. [Crossref]

11. Preusche I, Lamm C (2016) Reflections on empathy in medical education: What can we learn from social neurosciences? Adv Health Sci Educ Theory Pract 21: 235-249. [Crossref]

12. The Royal Society: Neuroscience; Implications for Education and Lifelong Learning. Brain Waves 2 (2011), February.

13. Slagter HA, Davidson RJ, Lutz A (2011) Mental training as a tool in the neuroscientific study of brain and cognitive plasticity. Front Hum Neurosci 5: 17. [Crossref]

14. Driemeyer J, Boyke J, Gaser C, Büchel C, May A (2008) Changes in gray matter induced by learning--revisited. PLoS One 3: e2669. [Crossref]

15. Nikolaidis A, Voss MW, Lee H, Vo LT, Kramer AF (2014) Parietal plasticity after training with a complex videogame is associated with individual differences. Front Hum Neurosci 8: 1-11. [Crossref]

16. Lent R, Tovar-Moll F (2015) How can development and plasticity contribute to understanding evolution of the human brain? Front Hum Neurosci 9: 208. [Crossref]

17. Ewan BM (2015) Epigenetics and learning. Trends Neurosci Educ 4: 108-111.

18. Dance A (2015) Neuroscience: Connectomes make the map. Nature 526: 147-149. [Crossref]

19. Zatorre RJ, Fields RD, Johansen-Berg H (2012) Plasticity in gray and white: 
neuroimaging changes in brain structure during learning. Nat Neurosci 15: 528-536. [Crossref]

20. Zammit AR, Ezzati A, Zimmerman ME, Lipton RB, Lipton ML, et al. (2017) Roles of hippocampal subfields in verbal and visual episodic memory. Behav Brain Res 317: 157-162. [Crossref]

21. Frank C, Land WM, Popp C, Schack T (2014) Mental representation and mental practice: Experimental investigation on the functional links between motor memory and motor imagery. Plus One 9: e95175. [Crossref]

22. Kraeutner SN, MacKenzie LA, Westwood DA, Boe SG (2016) Characterizing skill acquisition through motor imagery with no prior physical practice. J Exp Psychol Hum Percept Perform 42: 257-265. [Crossref]

23. Schack T, Essig K, Frank C, Koester D (2014) Mental representation and motor imagery training. Front Hum Neurosci 8: 328. [Crossref]

24. Lipsky RH (2013) Epigenetic mechanisms regulating learning and long-term memory. Int J Dev Neurosci 31: 353-358. [Crossref]

25. LeBeau AJ, Rissman EF (2013) Running-induced epigenetic and gene expression changes in the adolescent brain. Int J Dev Neurosci 31: 382-390. [Crossref]

26. Nan W, Wan F, Vai MI, Da Rosa AC (2015) Resting and Initial Beta Amplitudes Predict Learning Ability in Beta/Theta Ratio Neurofeedback Training in Healthy Young Adults. Front Hum Neurosci 9: 1 - 9. [Crossref]

27. Jeunet C (2015) Predicting mental imagery from psychometric questionnaires. Conference preecedings ACM Upsalla Sweden.

28. Dieckmann P, Molin Friis S, Lippert A, Ostergaard D (2009) The art and science of debriefing in simulation: Ideal and practice. Med Teach 31: e287-294. [Crossref]

29. Gerbier E, Toppino TC (2015) The effect of distributed practice: Neuroscience, cognition and education. Trends Neurosci Educ 4: 49-59.

30. Demirel D, Butler KL, Halic T, Sankaranarayanan G, Spindler D, et al. (2016) A hierarchical task analysis of cricothyroidotomy procedure for a virtual airway skills trainer simulator. Am J Surg 212: 475-484. [Crossref]

31. Bathalon S, Dorion D, Darveau S, Martin M (2005) Cognitive skills analysis, kinesiology and mental imagery in the acquisition of surgical skills. J Otolaryngol 34: 328-332. [Crossref]

32. Weller JM, Nestel D, Marshall SD, Brooks PM, Conn JJ (2012) Simulation in clinical teaching and learning. Med J Aust 196: 594. [Crossref]

33. Rohbanfard H, Proteau L (2013) Live vs. Video presentation techniques in the observational of motor skills. Trends Neurosci Educ 2: 27-32.

34. Taylor PJ, Russ-Eft DF, Chan DW (2005) A meta-analytic review of behavior modeling training. J Appl Psychol 90: 692-709. [Crossref]
35. Frank C, Land WM, Schack T (2013) Mental representation and learning: The influence of practice on the development of mental representation structure in complex action. Psychol Sport Exerc 14: 353-361.

36. Klasen M, Weber R, Kircher TT, Mathiak KA, Mathiak K (2012) Neural contributions to flow experience during video game playing. Soc Cogn Affect Neurosci 7: 485-495. [Crossref]

37. Rodriguez P, Zhou W, Barrett DW, Altmeyer W, Gutierrez JE, et al. (2016) Multimoda Randomized Functional MR Imaging of the Effects of Methylene Blue in the Human Brain. Radiology 281: 516-526. [Crossref]

38. Bavelier D, Green $\mathrm{CH}$, Pouget A, et al. Brain plasticity through the life span: Learning to learn and action video games. Annu Rev Neurosci 35: 391-416. [Crossref]

39. Ikanga J, Hill EM, MacDonald DA (2017) The conceptualization and measurement of cognitive reserve using common proxy indicators: Testing some tenable reflective and formative models. J Clin Exp Neuropsychol 39: 72-83. [Crossref]

40. Iaria G, Petrides M, Dagher A, Pike B, Bohbot VD (2003) Cognitive strategies dependent on the hippocampus and caudate nucleus in human navigation: Variability and change with practice. $J$ Neurosci 23: 5945-5950. [Crossref]

41. Mohamed AD (2014) Neuroethical issues in pharmacological cognitive enhancement Wiley Interdiscip Rev Cogn Sci 5: 533-549. [Crossref]

42. Pusic MV, Kessler D, Szyld D, Kalet A, Pecaric M, et al. (2012) Experience curves a an organizing framework for deliberate practice in emergency medicine learning. Acad Emerg Med 19: 1476-1480. [Crossref]

43. Herholz SC, Zatorre RJ (2012) Musical training as a framework for brain plasticity: behavior, function, and structure. Neuron 76: 486-502. [Crossref]

44. VanDongen EV, Kersten IHP, Wagner IC, Fernández G (2016) Physical exercise performed four hours after learning improves memory retention and increases hippocampal pattern similarity during retrieval. Curr Biol 26: 1-6. [Crossref]

45. Zeidan F, Johnson SK, Diamond BJ, David Z, Goolkasian P (2010) Mindfulness meditation improves cognition: Evidence of brief mental training. Conscious Cogn 19: 597-605. [Crossref]

46. Hardy JL, Nelson RA, Thomason ME, Sternberg DA, Katovich K, et al. (2015) Enhancing cognitive abilities with comprehensive training: A large, online, randomized, active-controlled trial. Plos One 10: e134467. [Crossref]

47. Alam F, Boet S, Piquette D, Lai A, Perkes CP, et al. (2016) E-Learning optimization: The relative and combined effects of mental practice and modeling on enhanced podcast-based learning-a randomized controlled trial. Adv Health Sci Educ Theory Pract 21: 789-802. [Crossref]

48. Bavelier D, Levi DM, Li RW, Dan Y, Hensch TK (2010) Removing brakes on adult brain plasticity: from molecular to behavioral interventions. J Neurosci 30: 14964 14971. [Crossref]

Copyright: (C2016 Martin M. This is an open-access article distributed under the terms of the Creative Commons Attribution License, which permits unrestricted use, distribution, and reproduction in any medium, provided the original author and source are credited. 